the best he can by seeing that the work of scientists is disseminated. The profit motive is not uppermost in his mind, and such profit as accrues is useful chiefly to ensure that the overall operation runs efficiently and as a subsidy for prestige loss-leaders like Leonardo (bridging arts and science), Archives of Oral Biology (for dentists) and Marcellia (The International Journal of Phytopathological Morphogenesis and Cecidology).

Among the numerous examples of subsidised services to science which $\mathrm{Mr}$ Maxwell says he can name off-hand is the Russian translating service which, although reduced after its first five years of operation, still produces of the order of 20,000 pages a year. The company's last published report showed a profit in the region of $£ 200,000$ a third of which came from books. (Trading profit for the year ended September, 1973 , was expected to be $£ 292,000$.

As a sign of his good intent, $\mathrm{Mr}$ Maxwell instances his plans for Tetrahedron, a top organic chemistry journal with some 5,000 subscriptions (mainly at the library rate of $£ 102$ a ycar, for which a library receives something like 12,000 pages of information). As an experiment, Tetrahedron is to be circulated in the form of expanded abstracts. Thirty papers in this form will occupy 60 printed pages, whereas the full papers would need 300 . The net result is a saving of $75 \%$ to $80 \%$ in costs to the subseriber, who simply writes for the detailed version of such papers as appeal to him, at no more than the photocopying cost. He also plans to cut subscription costs by developing a new typesetting technique for scientific material by harnessing the computer to the traditional archival type of journal; and when the annual rise of $10 \%$ in the volume of published literature makes it impossible for libraries to house any more magazines, he plans to be a leader in the field of microfiche and microfilm reproduction. Yes, he says, the portable microfiche reader will eventually oust the paper magazine. Which is all very fine with McLuhan, no doubt, but not much of an answer to the immediate problems of Alec Henderson, Charles Bubb, Kenneth Humphries and a cast of thousands of their library users.

\section{Soviet journals have their problems too}

\section{from our Soviet Correspondent}

The catalogue Gazety $i$ Zhurnaly SSSR (Periodicals of the USSR) for 1974 lists some 600 scientific and technological titles (excluding abstract journals), more than 500 of them in Russian, with Ukrainian-30 titles-as the next most prolific language. According to an article in Pravda by Candidate of Technical Sciences R. Ivanov (December 21, 1973) this plethora of specialist information is proving more and more difficult to digest, even on the assumption that a given reader will require to scan only the literature of his own speciality. A survey of $25 \%$ of the Soviet specialist journals, Ivanov claims, reveal some significant deficiencies.

Although it has been obligatory since 1967 for all scientific and technical publications to be accompanied by abstracts, only half of the journals studied did include them. Moreover, when abstracts occurred they had frequently not been revised by the editors with their intended readership in mind but were left in the unsatisfactory state in which they came from the authors, who write down as an abstract "Whatever God puts into their souls". Ivanov also criticises the practice of certain journals of printing the abstracts on narrow strips of coloured paper, bound into the front or back of the journal-this may save paper but wastes everyone else's time. Best of all, he maintains, is the practice of printing the abstracts on detachable, filable cards, which saves "many thousand of man hours". (One assumes that the Soviet reader, consulting the journal in a library, would never be so antisocial as to remove such an abstract to his private collection-or is there some security system to prevent this?)

Other major criticisms are the waste of paper at the end of articles (which could be utilised for announcements of forthcoming books, conferences and so on) and the absence in some $80 \%$ of the sampled journals of a submission date indicating the age of the material. Seventy-five per cent of the journals ignored the practice ("a sign of high culture") of putting the title, number and date of issue of the journal on every page-thus eausing specialists much delay in hunting through their collections of photocopies.

Faced with this abundance of journals, the increasing use of computer indexing and the physical and logistic problems of storage, Ivanov suggests not only such ideas as the introduction of standardised Union-wide identification symbols, and the printing of the abstract and bibliography together for simultaneous scanning (some of which problems are already under consideration by working groups) but the proposal, possible only in a very centralised system, that a single, unified physical format should be adopted for all scientific and specialist journals published in the Soviet Union for greater convenience in shelving.

\section{NIH leaders attacked and defended}

\section{Colin Norman, Washington}

THE longstanding dispute between officials at the National Institutes of Health and their superiors in the Nixon Administration has moved on to new battlegrounds-the correspondence columns of the Washington Post. The disagreements, which stem chiefly from the fact that the Administration has been attempting for the past year or so to centralise control over biomedical research policies in the Department of Health, Education and Welfare and the Office of Management and Budget, came to a fresh head recently when $\mathrm{Dr}$ John Sherman resigned as deputy director of NIH. He cited a number of intangible reasons for his departure, prominent among which was a complete lack of understanding between officials at NIH and administrators in the Department of Health, Education and Welfare (see Nature, 247, 172; 1974).

The Washington Post then criticised HEW officials in an editorial, a move which stung Dr Charles C. Edwards, Assistant HEW Secretary for Health, into firing off a letter to the newspaper, in turn criticising the "inadequate leadership" at NIH. Not surprisingly, several scientists at NIH drafted a reply to Edwards's letter, circulated it around the NIH campus for a couple of days during which it gathered 460 signatures, and dispatched it to the Post last week.

The Post editorial had called on the Nixon Administration to give $\mathrm{NIH}$ the autonomy that it has had in the past, to restore its "world-wide reputation for excellence". But Edwards argued in his letter than an institution which spends $\$ 2,000$ million a year cannot be completely insulated from budgetary and managerial control. He also maintained that confidence in NIH has "diminished in the past through inadequate leadership and a misguided sense of the place of research in the nation's efforts to solve its health problems."

What really stung NIH scientists, however, was a reference in Edwards's letter to the fragmentation which has been taking place at NIH, particularly the increased autonomy that has been given to the National Cancer Institute. "If the NIH leadership had been more receptive and responsive", he argued, "we might not have witnessed the removal of the cancer research effort from the administrative control of $\mathrm{NIH}$, a move that threatens the further dissolution of biomedical research efforts".

What Dr Edwards seems to have forgotten is that when Congress was debating the National Cancer Act, the NIH leadership fought a battle within the Administration to prevent the National 